\title{
Adrenal corticosteroids and the Kamin effect*
}

\author{
NANCY SNIDER, HUGH A. MARQUIS, MANUAL BLACK \\ and MILTON D. SUBOSKI \\ Queen's University, Kingston, Ont., Canada
}

Adrenalectomy and dexamethasone blocking of adrenocorticotropin (ACTH) release in adrenalectomized and sham-operated rats did not affect time-dependent changes in performance following discriminated avoidance conditioning. Adrenalectomized rats also yielded the U-shaped intersession interval function characteristic of the Kamin effect in shuttlebox conditioning. The use of Sprague-Dawley rats precluded the possibility that time-dependent performance changes following aversive conditioning in adrenalectomized rats are the product of postoperatively developed accessory adrenal tissue. The Kamin effect occurs independent of pituitary-adrenal function.

Performance in the two-way shuttlebox is a U-shaped function of the interval between an initial training session and a subsequent test session, the well-replicated Kamin effect. Brush \& Levine (1966; Levine \& Brush, 1967) and King (1969) have suggested that the initial performance decrement is directly related to the level of circulating corticosteroids, which shows a parallel decrease following avoidance conditioning. Indirect evidence against this hypothesis was supplied by Marquis \& Suboski (1969), who obtained the Kamin effect in hypophysectomized rats, and by Kasper-Pandi, Hansing, \& Usher (1970), who obtained the Kamin effect when the corticosteroid response was blocked by dexamethasone injections. Direct evidence against the hypothesis was provided by Suboski, Marquis, Black, \& Platenius (1970). They found an apparently normal Kamin effect in adrenalectomized Long-Evans rats. However, Hahn (1969) has reported that $50 \%$ of a sample of Long-Evans rats had accessory adrenal tissue following bilateral adrenalectomy, as compared to $18 \%$ of Sprague-Dawley rats. Because of the possibility that a substantial proportion of the rats used by Suboski et al (1970) retained the corticosteriod response following adrenalectomy, the present experiment was conducted using Sprague-Dawley rats. Adrenal function in time-dependent performance changes were investigated in one-trial

*We thank Eileen Simon for assistance in data collection. This research was supported by Grant No. 161 from the O..' ?rio Mental Health Foundation. discriminated avoidance and two-way shuttlebox conditioning. SUBJECTS

The Ss were 105 male albino rats, $300-350 \mathrm{~g}$ in weight, obtained from Holtzman Co. Postoperatively, all of the Ss were allowed ad lib access to food and a $1 \% \mathrm{NaCl}, 5 \%$ sucrose solution in water.

\section{APPARATUS}

The discriminated avoidance apparatus has been previously described (Suboski, Spevack, Litner, \& Beaumaster, 1969). Briefly, it consisted of a triangular-shaped open field illuminated by a $100-\mathrm{W}$ flood lamp. The acute angles of the open field were truncated by small enclosed chambers with guillotine doors. The chambers were differentiated by position, color (black or white), and the shape of the openings (round or square). The floor of the open field was white plastic; in the small chambers, stainless steel grids connected to a scrambled shock source were set to deliver a 2-mA shock. The shuttlebox was that used in previous experiments from this laboratory (Marquis \& Suboski, 1969; Suboski et al, 1970).

About 24 days prior to the beginning of experimentation, 42 randomly selected $S$ s underwent bilateral adrenalectomy via the dorsal approach under ether anesthesia. An additional 42 Ss received a sham operation in which the adrenals were exposed but not removed. The remaining 21 Ss were unoperated.

The discriminated avoidance training procedure has been previously described (Suboski et al, 1969). The Ss were given four pretraining trials, alternated free and forced choice, one trial per day. On free-choice trials, Ss were permitted to enter either of the small chambers; on forced-choice trials the opening to the previously chosen chamber was blocked by the door. On the fifth (free choice) day, the grid floor of whichever chamber was chosen was charged with scrambled shock after $\mathbf{S}$ entered, and the shock continued until $S$ left the chamber. Twer ty-four and $6 \mathrm{~h}$ prior to the sixth (test) trial, 21 operated and 21 sham-operated $S$ s received injections of dexamethasone $(500 \mathrm{mg} / 100 \mathrm{~g}$ body weight), a powerful inhibitor of adrenocorticotropic hormone (ACTH), subcutaneously at the back of the neck. The rest of the operated and sham-operated $S$ s received saline injections. Seven Ss from each treatment combination were returned to the open field for a free-choice test trial at each of three postshock intervals, $10 \mathrm{sec}, 1,000 \mathrm{sec}(16 \mathrm{~min}$, 40 s e c), or 100,000 sec (approximately $28 \mathrm{~h}$ ). Response latency and small chamber choice were recorded.

Shuttlebox training was conducted approximately 3 weeks after completion of discriminated avoidance training. Thirty animals were used from each of the operated, sham-operated, and unoperated groups. Of the operated and sham-operated Ss, 15 had received dexamethasone injections and 15 had received saline. Each $S$ received 30 training trials. in the shuttlebox, followed by 20 test trials. The training procedure was that used in previous experiments from this laboratory (Marquis \& Suboski, 1969; Suboski et al, 1970). Ten Ss from each operation condition were tested at each of three intersession intervals, $1 \mathrm{~min}, 1 \mathrm{~h}$, or $24 \mathrm{~h}$. Type of prior injection was counterbalanced for operated and sham-operated groups.

\section{RESULTS}

Discriminated Avoidance

Figure 1 shows mean response latency to enter one of the small chambers on the test trial. Since only $13 \%$ of the Ss had test latency scores over $30 \mathrm{sec}$, in order to reduce the within-group variance, $30 \mathrm{sec}$ was used as the maximum score. An analysis of variance revealed the training-test interval to be a significant source of variance $(F=9.48, \quad \mathrm{df}=2 / 90$, $\mathrm{p}<.01)$. Both the linear $(\mathrm{F}=12.07$, 
$p<.01)$ and quadratic $(F=6.90$, $\mathrm{p}<.05)$ trends across intervals were significant. Both type of treatment $(F=1.57, \quad \mathrm{df}=4 / 90)$ and the interaction between type of treatment and training-test interval $(F=1.18$, $\mathrm{df}=8 / 90$ ) were nonsignificant. All except 10 of the Ss reversed choice between the training and test trials. Chi-square tests revealed no significant differences in choice as a function of experimental treatment.

\section{Shuttlebox}

Figure 2 displays mean percentage avoidances for the test session in the two-way shuttlebox. Avoidance performance was a U-shaped function of the intersession interval, indicating the occurrence of the Kamin effect, for all three operation conditions. An analysis of variance conducted on percentage avoidances for the test session revealed intersession interval to be significant $(F=10.23, d f=2 / 81$, $\mathrm{p}<.01)$. Neither operation condition $(\mathrm{F}=.85, \mathrm{df}=2 / 81)$ nor the interaction between intersession interval and operation condition ( $F=2.04, \mathrm{df}=4 / 81$ ) were significant. Furthermore, neither the linear $(F=1.60)$ nor quadratic $(F=2.47)$ trends across intersession interval depended upon operation condition. However, an analysis of the first session data (not shown), which included intersession interval as a nominal variable, yielded a significant Operation Condition by Intersession

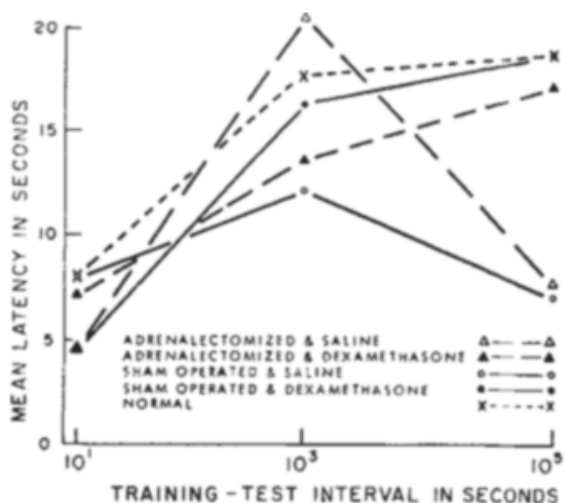

Fig. 1. Discriminated avoidance response latency for the five treatment combinations as a function of the interval between training and test.

Interval interaction, apparently the result of bias in assignment of $S s$ to intersession interval groups. Consequently, difference scores (not shown) were obtained for each $\mathbf{S}$ by subtracting the percentage avoidance for the first 10 trijals of the test session from the percentage avoidance for the last 10 trials of the training session. Analysis of these data also yielded a significant effect only of the intersession interval $(F=8.19$, $\mathrm{df}=2 / 81, \mathrm{p}<.01$ ). Again, orthogonal comparisons revealed no significant differences in trend across intervals among the operation conditions.

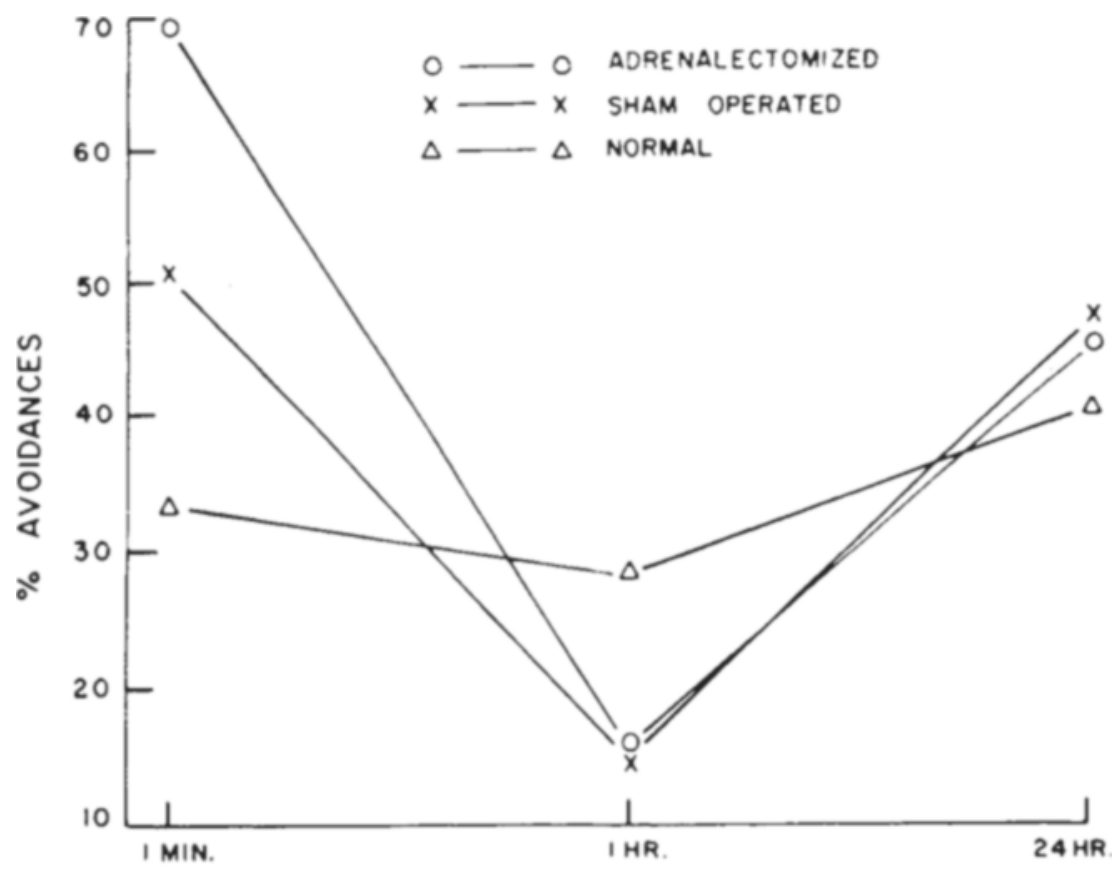

INTERSESSION INTERVAL

Fig. 2. Mean percentage avoidances in the test session of shuttlebox conditioning for the three operation conditions as a function of the intersession interval.
DISCUSSION

The present experiments indicate that the time-dependent changes in performance which follow aversive conditioning occur independent of pituitary-adrenal function. Adrenalectomy eliminates the corticosteriod response and accentuates ACTH release, and dexamethasone injections, in a considerably smaller dose level than that used in the present experiment, blocks ACTH release and the corticosteroid response (Kasper-Pandi et al, 1970). Neither procedure had any reliable effect on the time-dependent increase in response latency following discriminated avoidance training. Similarly, adrenalectomized rats yielded an unimpaired Kamin effect in two-way shuttlebox conditioning. Furthermore, the use of Sprague-Dawley rats in the present experiments effectively precluded the possibility that the $\mathrm{Kamin}$ effect occurs in adrenalectomized rats because of the postoperative development of accessory adrenal tissue. Evidence that the Kamin effect occurs in hypophysectomized (Marquis \& Suboski, 1969), adrenalectomized ( Suboski et al, 1970), and dexamethasone-blocked (Kasper-Pandi et al, 1970) rats overwhelmingly indicates the lack of any relationship between pituitary-adrenal function and the Kamin effect.
BRUSH, F. R., \& LEVINE, $S$ Adrenocortical activity and avoidance learning as a function of time after fear conditioning. Physiology \& Behavior, $1966,1,309-311$

HAHN, E. W. Survival of adrenalectomized Long-Evans and Sprague-Dawley rats. Laboratory Animal Care, 1969, 19, 724-726.

KASPER-PANDI, P., HANSING, R., \& USHER $D$. The effect of dexamethasone blockade of ACTH release on avoidance learning. Physiology \& Behavior, 1970, 5, 361-363.

KING, M. G. Stimulus generalization of conditioned fear in rats over time: olfactory cues and adrenal activity. Journal of Comparative \& Physiological Psychology, 1969, 69, 590-600.

LEVINE, S., \& BRUSH, F. R. Adrenocortical activity and avoidance learning as a function of time after avoidance training. Physiology \& Behavior, 1967, 2, 385-388.

MARQUIS, H. Ȧ., \& SUBOSKI, M. D. Hypophysectomy and ACTH replacement in the incubation of passive and shuttle box avoidance responses. Proceedings of the 77th Annual Convention of the APA, $1969,4,207-208$.

SUBOSKI, M. D., MARQUIS, H. A. BLACK, M., \& PLATENIUS, P. Adrenal and amygdala function in the incubation of aversively conditioned responses. Physiology \& Behavior, 1970, 5, 283-289. SUBOSKI, M. D., SPEVACK, A. A.. LITNER, J., \& BEAUMASTER, E. Effects of ECS following one-trial discriminated avoidance conditioning. Neuropsychologia, 1969, 7, 67-78. 